
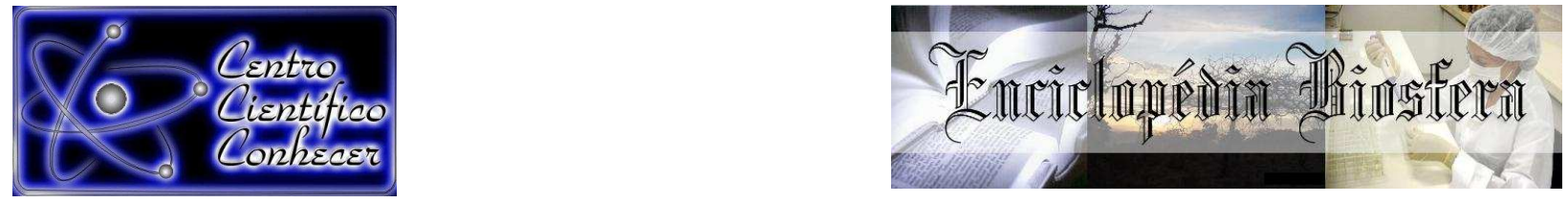

\title{
ANÁLISE DO ASPECTO PRODUTIVO DAS INDÚSTRIAS MADEIREIRAS DE PROCESSAMENTO PRIMÁRIO DA REGIÃO METROPOLITANA DE BELÉM
}

\author{
Wilson Fernandes Ramos ${ }^{1}$, Maria de Lourdes Pinheiro Ruivo ${ }^{2}$, Larissa Melo de \\ Sousa $^{3}$
}

1. Mestre em Ciências Ambientais, Universidade Federal do Pará/UFPA, Belém, PA, Brasil. (wilson.f.ramos18@hotmail.com)

2. Pesquisadora Titular. Museu Paraense Emilio Goedi/MCTI, Belém (PA), Bolsista CNPQ.

3. Doutoranda em Ciências florestais, Universidade Federal Rural da Amazônia/Ufra, Belém, PA, Brasil.

Recebido em: 03/10/2016 - Aprovado em: 21/11/2016 - Publicado em: 05/12/2016 DOI: 10.18677/EnciBio 2016B 004

\begin{abstract}
RESUMO
As serrarias são indústrias que realizam o processamento primário da madeira. Essas indústrias têm grande importância na socioeconômica da Amazônia, gerando inúmeros benefícios nos municípios onde estão inseridas. O objetivo deste trabalho foi descrever as principais características do processo produtivo das serrarias da Região Metropolitana de Belém (RMB), estado do Pará, como o porte, o número de funcionários, as espécies florestais utilizadas, os principais maquinários e 0 rendimento operacional. Para tal, o número de serrarias foi levantado junto aos órgãos competentes, a fim de realizar uma amostragem não-probabilística voluntária, e, assim, chegou-se numa amostra de 19 empresas localizadas na RMB. Utilizou-se como instrumento de pesquisa a entrevista semi-estruturada, além de observações in loco. A análise dos dados foi feita através da estatística descritiva e do teste $t$ de student. Verificou-se que 18 serrarias apresentam porte pequeno e apenas uma possui porte médio. Há uma média de 43 funcionários e um total de 811. As serrarias utilizam em média 11 espécies florestais em seu processo produtivo, sendo que as principais são Jatobá (Hymenaea courbaril L.) e Maçaranduba (Manilkara huberi Ducke). Os principais maquinários utilizados são a serra fita e circular e a destopadeira. A idade destes varia de 11 a 20 anos. Essas empresas consomem um montante de $230,1 \mathrm{mil} \mathrm{m}^{3}$ de madeira em tora anualmente e apresentam um rendimento operacional médio de $52 \%$. Conclui-se que as serrarias utilizam um número grande de espécies florestais que, aliado a idade elevada do maquinário, podem contribuir para o baixo Rendimento operacional.
\end{abstract}

PALAVRAS-CHAVE: Amazônia, Processamento de madeira, serrarias

\section{ANALYSIS OF ASPECT PRODUCTION INDUSTRIES TIMBER PRIMARY PROCESSING OF METROPOLITAN REGION OF BELÉM}

\footnotetext{
ABSTRACT

The industries of the primary processing of wood have great importance in the Amazon socioeconomic, generating numerous benefits in the regions where they ENCICLOPÉDIA BIOSFERA, Centro Científico Conhecer - Goiânia, v.13 n.24; p.39 2016
} 
operate. The aim of this study was to describe the main characteristics of the production in the metropolitan region of Belém City (RMB), Pará State, as size, number of employees, forest species used, main machinery and high operational efficiency. For this, the number of industries has been obtained with the competent environmental authorities to conduct a voluntary non-probability sampling. We reached on a sample of 19 companies located in RMB. It was used as a research tool semi-structured interviews, and on-site observations. The data analysis was done using descriptive statistics and Student t test. It was found 18 small sawmills and only one of medium size. There is an average of 43 employees and a total of 811. The industries use an average of 11 forest species, in its production process, and the main ones are Jatoba (Hymenaea L.) Maçaranduba (Manilkara huberi Ducke). The main machines used are the saw blade and circular and "destopadeira". The age of this machinery ranges from 11 to 20 years. These companies consume an amount of 230,100 cubic meters of logs annually and have an average operating income of $52 \%$. We conclude that the industries use a large number forest species that combined with high age of the machinery can contribute to lower operating income.

KEYWORDS: Sawmills, Wood processing, Amazon

\section{INTRODUÇÃO}

A Indústria madeireira é um dos setores mais fortes e importantes da economia mundial, porquanto a madeira como principal matéria-prima é um produto versátil que pode ser usado extensivamente em vários setores da economia. Ademais, essa indústria é de grande representatividade na economia brasileira e seus produtos estão incluídos no ranking dos que mais contribuem para a geração de superávits comerciais (NUNES et al., 2012).

Dentro desse setor, estão as indústrias de processamento primário, representadas, principalmente, pelas serrarias, que são indústrias do setor madeireiro que realizam o processamento primário e algumas vezes secundário da madeira. Essas indústrias utilizam, em seu processamento, a madeira bruta, cujos produtos beneficiados são usados em inúmeros setores da economia, como na fabricação de móveis, cabos de ferramentas e, principalmente, na construção civil, como pranchas, ripas, caibros, entre outros derivados da madeira serrada (IWAKIRI et al., 2012).

$\mathrm{Na}$ Amazônia brasileira, essas indústrias são muito expressivas devido à grande disponibilidade de matéria-prima (RIVERO et al., 2011). A região responde por mais de $90 \%$ da produção florestal de áreas naturais do Brasil, sendo o estado do Pará um dos mais relevantes nesse setor. Ademais, a indústria madeireira está entre as principais atividades econômicas do estado, juntamente com o setor mineral e a agropecuária (VERÍSSIMO et al., 2006). No Brasil, há um grande crescimento da demanda por produtos madeireiros, abrangendo tanto a indústria madeireira quanto a moveleira (REZENDE et al., 2014; VALVERDE et al., 2014).

Em 2009 foram identificadas 71 polos madeireiros na Amazônia legal, que são localidades cujo volume de extração e consumo anual de madeira em tora é igual ou superior a 100 mil metros cúbicos. Dentro desses polos, há aproximadamente 2.227 empresas que realizam o processamento primário, secundário e terciário da madeira na Amazônia legal (SFB \& IMAZON, 2010). No estado do Pará, o número de empresas do setor de base florestal é de cerca de 
1.067, que abrange empresas que realizam desde o processamento inicial até as beneficiadoras e movelarias.

Dentre esse montante, as serrarias e microsserrarias apresentam grande representatividade. Essas empresas geram cerca de 92.424 mil empregos diretos e indiretos, com uma receita bruta de US $\$ 1$ bilhão. O consumo de madeira no estado do Pará foi, em 2009, de aproximadamente 6.6 milhões de metros cúbicos de madeira em tora e uma produção de 2.55 milhões de metros cúbicos de madeira serrada ou beneficiada (SFB; IMAZON, 2010). Ressalta-se que o valor de venda da madeira processada vem aumentando nos últimos anos (SILVA \& MARQUES, 2012).

Uma das problemáticas envolvendo esse setor é a questão do baixo rendimento operacional, o que pode gerar um aumento no consumo de madeira, acarretando uma carência dessa matéria-prima no futuro. Com isso, a exigência por esse setor da matéria-prima é cada vez mais intensa, gerando uma pressão sobre as florestas, pois a maior parte dessa madeira vem de florestas naturais que ocupam mais de $97 \%$ do total de florestas do Brasil (SFB, 2013).

Dessa forma, as indústrias madeireiras do estado do Pará apresentam, em média, um rendimento operacional de $38 \%$, sendo considerado baixo quando comparados com o rendimento médio das serrarias brasileiras que são de 60 a $80 \%$ (BATISTA et al., 2013). Porém, na região Amazônica, o processamento da madeira nativa chega a perdas de 59\% (SFB \& IMAZON, 2010), caracterizando um cenário de baixa tecnologia associado a um mau aproveitamento da madeira.

Assim, as práticas atuais de exploração dão continuidade a um modelo de uso dos recursos naturais, marcados pela degradação e devastação da floresta (SCARIOT, 2011). Para BECKER (2010), o grande desafio para a região Amazônica é utilizar sua biodiversidade e recursos, sem destruir, o seu valioso patrimônio natural. Através do exposto, verifica-se que a indústria madeireira no estado do Pará apresenta uma inquestionável importância socioeconômica, devido à grande geração de emprego e renda, além de impostos e tributos para o poder público. Porém, essa indústria apresenta um rendimento operacional baixo, levando a um alto consumo de madeira em tora, mas com uma baixa produção de madeira serrada. Com isso, o conhecimento da realidade desse setor na região de Belém é de grande importância, tanto para o conhecimento dos problemas, quanto para a propositura de soluções.

Assim, o objetivo deste trabalho foi descrever as principais características do processo produtivo das indústrias madeireiras de processamento primário (serrarias) da região metropolitana de Belém, estado do Pará, considerando o porte, o número de funcionários, as espécies florestais utilizadas, os principais maquinários e 0 rendimento operacional.

\section{Área de Estudo}

\section{MATERIAL E MÉTODOS}

A área de estudo foi a região metropolitana de Belém do Pará - PA (Figura 1), exceto o município de Santa Isabel do Pará. Essa região metropolitana foi criada em 1973 e atualmente é formada pelos municípios de Ananindeua, Belém, Benevides, Marituba, Santa Bárbara do Pará e Santa Isabel do Pará. Os municípios da região metropolitana de Belém pertencem à mesorregião metropolitana de Belém e à microrregião Belém (PARÁ, 2014). 
A área de estudo encontra-se em uma região climática classificada como Af segundo Köppen, sendo formada por um clima quente e úmido, com temperatura média anual de $26^{\circ} \mathrm{C}$, com umidade média relativa do ar girando em torno de $90 \%$, o índice pluviométrico entre $2.300 \mathrm{~mm}$ a $3.000 \mathrm{~mm}$ por ano.

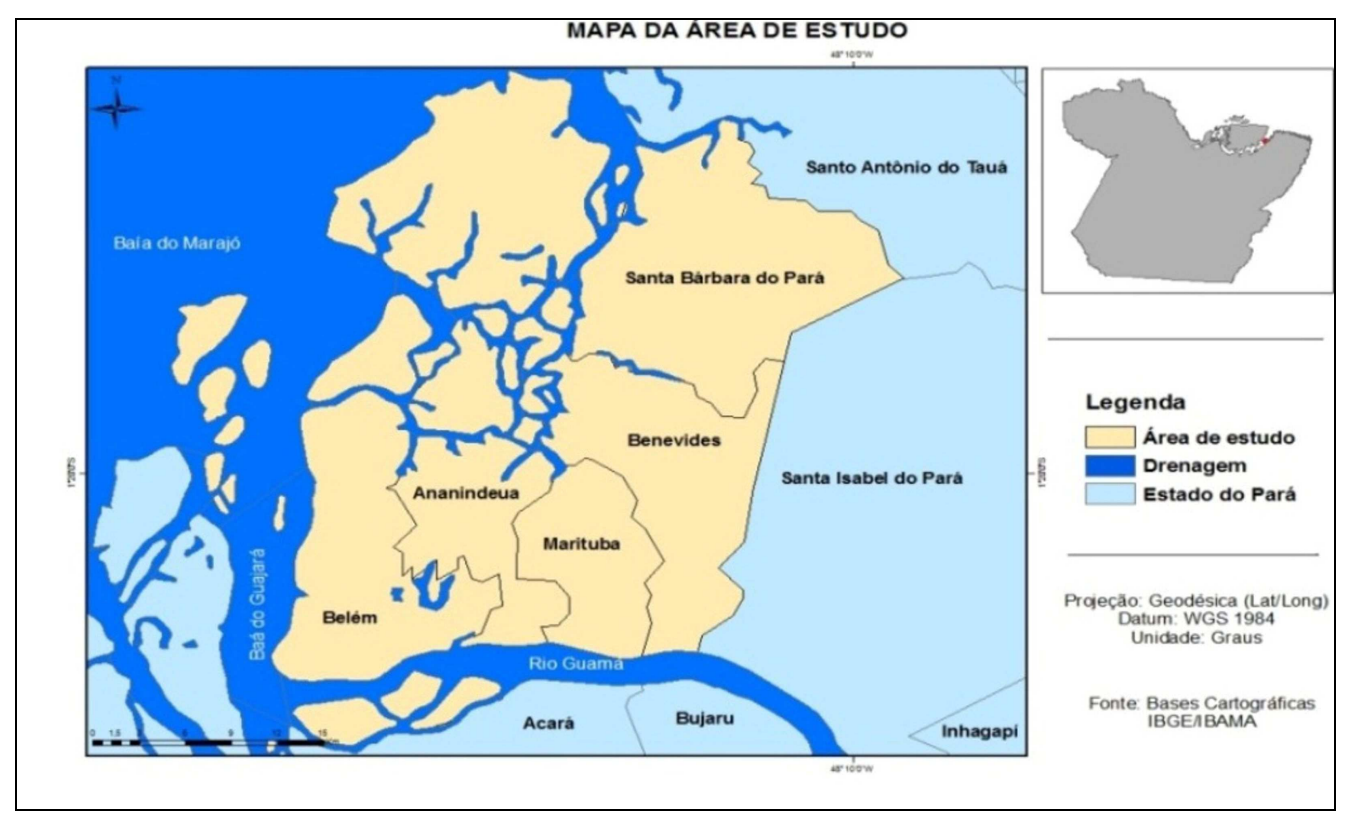

FIGURA 1 - Mapa da Região Metropolitana de Belém Fonte: Base cartográfica IBGE (2010)

\section{Levantamentos iniciais}

O número de indústrias madeireiras da região metropolitana de Belém (RMB) foi obtido junto à Secretária Estadual do Meio Ambiente (SEMA) e no sítio da Associação das Indústrias Exportadoras de Madeira do Estado do Pará (AIMEX) no período de setembro de 2014 a fevereiro de 2015. Assim, levantou-se um montante de 72 empresas que realizam o processamento primário (serrarias).

Para se definir a amostra, foi escolhida a técnica de amostragem nãoprobabilística por conveniência, a qual é construída por unidades (empresas) que se disponibilizam voluntariamente para integrar a amostra, ou seja, o pesquisador seleciona membros da população mais acessíveis. Dessa forma, chegou-se em uma amostra de 19 empresas, as quais aceitaram participar da pesquisa, todas localizadas na região metropolitana de Belém. Após essa definição, foi feito as visitas as essas empresas no período de maio a julho de 2015.

\section{Coleta de dados}

Para a coleta de dados nas referidas empresas, utilizou-se a entrevista semiestruturada como instrumento de pesquisa, a qual é feita presencialmente. Esse instrumento conjuga perguntas abertas e fechadas e foi escolhido por apresentar um maior contato do pesquisador com a população, cuja informação se deseja obter, e por facilitar a compreensão das perguntas por parte dos entrevistados (PRODANOV \& FREITAS, 2013).

Ademais, utilizou-se a observação in loco como técnica de coleta de dados, por meio da qual utilizam-se os sentidos na obtenção de dados de determinados aspectos da realidade. Essa é uma técnica muito utilizada nas ciências sociais para a coleta de dados qualitativos (PRODANOV \& FREITAS, 2013). 
O porte da serraria foi avaliado de acordo com o volume de madeira serrada por dia ou turno de trabalho, usando a classificação feita por ROCHA (2002), o qual considera micro serraria a que produz menos de $10 \mathrm{~m} /$ dia madeira serrada; serraria de pequeno porte, de $10 \mathrm{~m}^{3} / \mathrm{dia}$ até $50 \mathrm{~m}^{3} /$ dia de madeira serrada; serrarias de médio, entre $50 \mathrm{~m}^{3} / \mathrm{dia}$ até $100 \mathrm{~m}^{3} /$ dia madeira serrada; e serraria de grande porte, a qual apresenta uma produção de mais de $100 \mathrm{~m}^{3} /$ dia de madeira serrada.

As variáveis: número de funcionários, número de espécies florestais utilizadas, principais maquinários e a idade média desses, bem como o consumo de toras, produção de madeira serrada, foram coletadas através de perguntas constantes no formulário, que foram feitas junto aos responsáveis técnicos ou proprietários, que as forneciam de acordo com a documentação existente nas serrarias, notas fiscais e outros documentos.

Já o rendimento operacional foi calculado com base no Balanço de matérias das serrarias, essa técnica pode ser usada também para estimar a quantidade de resíduos gerados nas indústrias de base florestal (MELO et al., 2012). Sendo assim, através da diferença entre quantidade de tora consumida e a de madeira processada, obteve-se o rendimento médio das empresas visitadas.

\section{Análise de dados}

Os dados coletados foram analisados através da estatística descritiva, que "compreende o manejo dos dados para resumí-los ou descrevê-los" sendo expostos através de tabelas, utilizando também a média e os valores máximo e mínimo. Utilizou-se para essa análise o programa Excel do software Microsoft Office 2007. Ademais, utilizou-se, o Teste $t$ de Student resumo amostral para a variável rendimento operacional médio das serrarias da RMB, com o objetivo de verificar se há diferença estatisticamente significativa entre o rendimento encontrado na presente pesquisa $(52 \%)$, com o rendimento encontrado pelo SFB \& IMAZON (2010), no estado do Pará (38,2\%) e a Amazônia Legal (41\%). Esse teste é utilizado para comparar médias de duas populações distintas (BLAIR \& TAYLOR, 2013). Para tal, utilizou-se o programa BioEstat 5.3.

\section{RESULTADOS E DISCUSSÃO}

Entre as 19 serrarias levantadas neste estudo, cinco pertencem ao município de Belém, duas ao de Ananindeua, sete ao município de Benevides, três se localizam em Santa Bárbara do Pará e uma em Marituba (Figura 2).

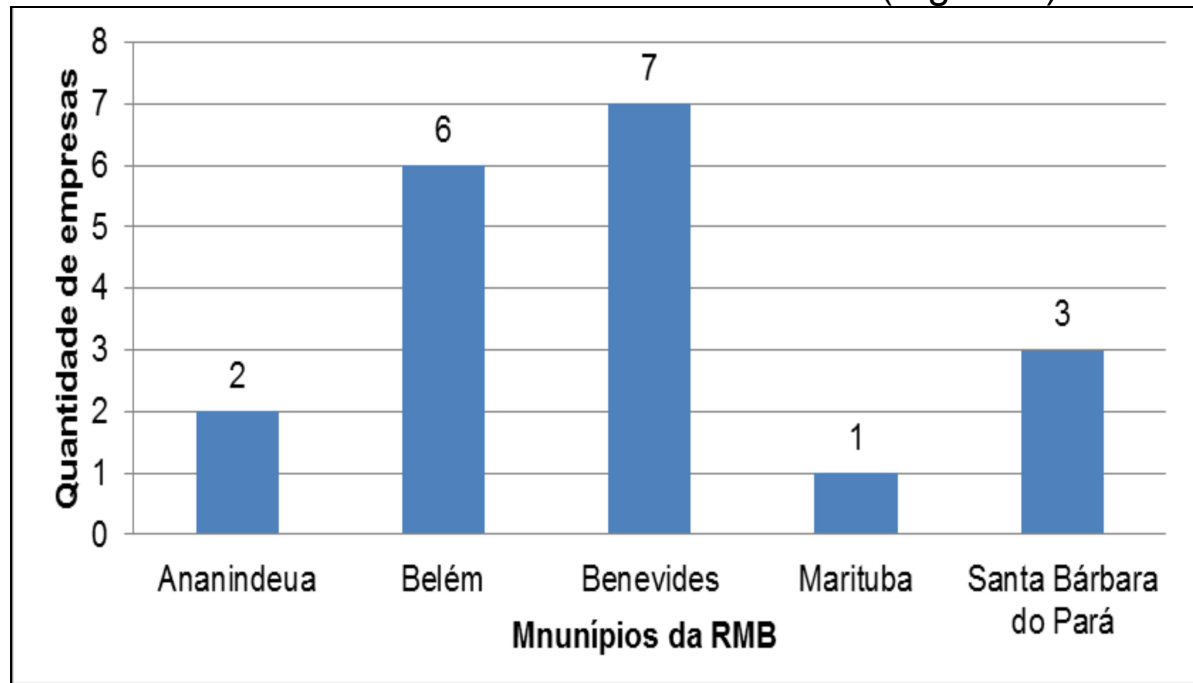

FIGURA 2 - Número de serrarias visitadas nos cinco municipios da RMB. ENCICLOPÉDIA BIOSFERA, Centro Científico Conhecer - Goiânia, v.13 n.24; p.43 
Verificou-se que o porte das serrarias, considerando a classificação feita por ROCHA (2002), apresentou-se da seguinte forma: 1 serraria foi classificada como de médio porte, ou seja, apresentou produção de $50 \mathrm{~m}^{3} / \mathrm{dia}$ a $100 \mathrm{~m}^{3} /$ dia de madeira serrada, e o restante, 18 serrarias, foram classificadas como de pequeno porte, apresentando uma produção de $10 \mathrm{~m} / \mathrm{dia}$ a $50 \mathrm{~m}^{3 /}$ dia madeira serrada. Esses valores corroboram com estudos realizados por PAIXÃO et al. (2014), os quais levantaram que das quatro serrarias no município de Rolim de Moura no estado de Rondônia, todas apresentaram porte pequeno.

Em relação à variável número de funcionários, as 19 serrarias visitadas apresentaram uma média de 43 colaboradores empregados diretamente em seu processo produtivo, com empresas apresentando valores de 20 e outras com, 70 funcionários, mostrando uma certa diferença no número de empregados. No total, essas serrarias empregaram juntas 811 trabalhadores de forma direta. Esse montante foi bem menor do que o levantado pelo SFB \& IMAZON (2010) que registraram 13 mil empregos diretos e indiretos em Belém.

Essa diferença é devida aos referidos Institutos levarem em consideração os empregos indiretos, além de considerar as empresas de processamento secundário. Porém, os valores levantados nesta pesquisa expõem a relevância socioeconômica dessas empresas, gerando um número expressivo de empregos diretos na região metropolitana de Belém.

Nas serrarias pesquisadas, foi verificada a utilização de 27 espécies florestais diferentes (Quadro 1). Esses números são próximos aos que foram encontrados por Gomes \& Sampaio (2004), os quais levantaram 23 espécies utilizadas em três serrarias na região metropolitana de Belém, e por VERÍSSIMO et al. (2006), que encontraram a utilização de 15 espécies em serrarias e micro-serrarias no estado do Pará. Contudo, ressalta-se que aumentou o número de espécies florestais utilizadas no processo produtivo das serrarias sendo um dos motivos a exploração em novas áreas como o Baixo Amazonas.

QUADRO 1 - Nome comercial e cientifico das espécies utilizadas nas serrarias da RMB

\begin{tabular}{|l|l|}
\hline \multicolumn{1}{|c|}{ Nome comercial } & \multicolumn{1}{c|}{ Nome cientifico } \\
\hline Acapú & Vuouacapua americana Aubl \\
\hline Andiroba & Carapa guianenses Aubl. \\
\hline Angelim-amargoso & Vatairea paraensis Ducke \\
\hline Angelim-pedra & Hymenolobium petraeum Ducke \\
\hline Angelim-vermelho & Dinizia excelsa Ducke \\
\hline Arurá-branco & Osteophloeum platyspermum A. DC Warb. \\
\hline Cumaru & Dipteryx odorata Willd. \\
\hline Cupiúba & Goupia glabra Aubl. \\
\hline Faveiro & Parkia sp. \\
\hline Guajará & Chrysophyllum venezuelanense \\
\hline Ipê-amarelo & Tabebuia serratifolia (Vahl) Nichols \\
\hline Jatobá & Hymenaea courbaril L. \\
\hline Louro-vermelho & Sextonia rubra (Mez.) C. K. Allen \\
\hline Maçaranduba & Manilkara huberi Ducke \\
\hline
\end{tabular}




\begin{tabular}{|l|l|} 
Marupá & Simarouba amara Aubl. \\
\hline Muiracatiara & Astronium lecointei Ducke \\
\hline Mururé & Brosimum sp. \\
\hline Parapará & Jacaranda copaia (Aubl.) D. Don \\
\hline Pau-amarelo & Euxylophora paraensis Hub. \\
\hline Piquiá & Cariocar villosum (Aubl.) Pers. \\
\hline Rouxinho & Peltogyne sp. \\
\hline Sucupira-pele de sapo & Bowdichia nitida Spruce \\
\hline Sucupira-preta & Diplotropis purpurea (Rich) Amsh. \\
\hline Tatajuba & Bagassa guianensis Aubl. \\
\hline Tauari & Couratari sp. \\
\hline Timborana & Piptadenia suaveolens Miq. \\
\hline Virola & Virola sp. \\
\hline
\end{tabular}

As 19 empresas apresentaram um consumo médio de 11 espécies florestais em seu processamento, com empresas processando apenas uma espécie e outras com até 21 espécies florestais. Dentre as espécies levantadas na pesquisa, as mais citadas pelas serrarias foram Angelim-pedra (Hymenolobium petraeum Ducke), Muiracatiara (Astronium lecointei Ducke), Jatobá (Hymenaea courbaril L.) e Maçaranduba (Manilkara huberi Ducke), que apresentaram frequência de 15, 15, 16 e 17 empresas, respectivamente. BARBOSA et al. (2001) estimam que existam cerca de 6.000 espécies arbóreas na Amazônia, das quais 230 espécies apresentam potencial de aproveitamento pela indústria madeireira, entretanto $80 \%$ da produção utiliza apenas 50 espécies.

Quanto aos maquinários, como são empresas que fazem o processamento primário, todas apresentaram os maquinários básicos para a sua produção como serra fita, serra circular e sala de amolação ou afiação, ao passo que 12 apresentaram destopadeiras, oito plainas, cinco apresentaram laminadoras e refiladeiras, e duas tinham faqueadoras como maquinário (Figura 3).

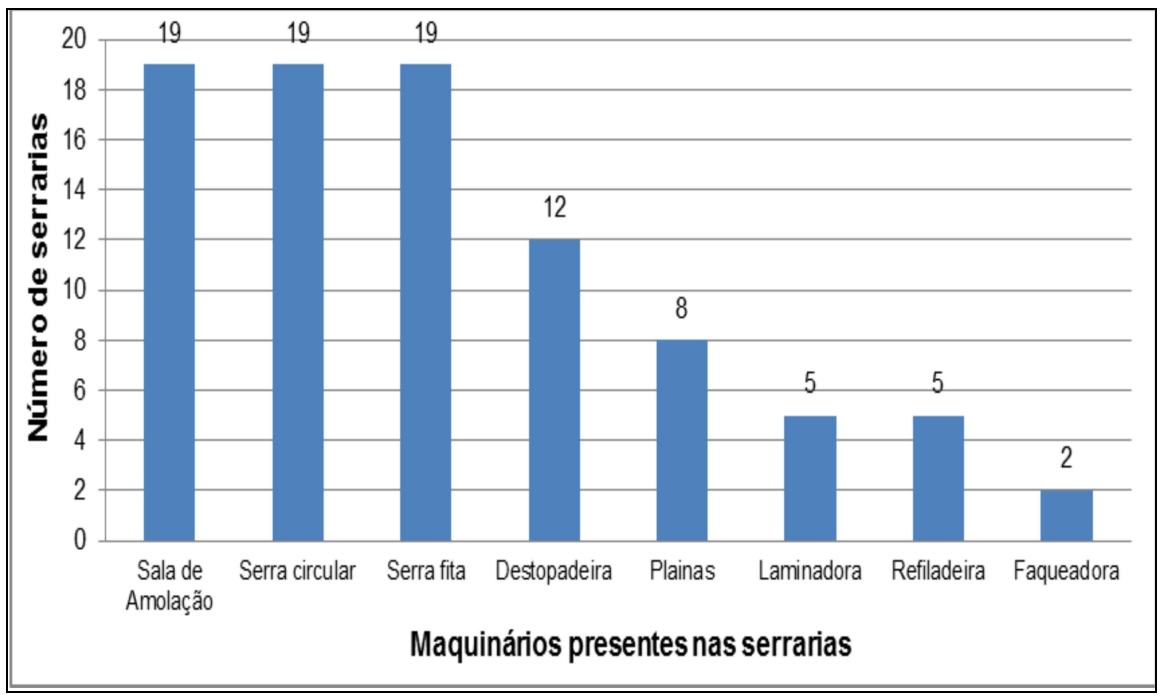

FIGURA 3 - Quantidade dos principais maquinários utilizados no processamento da madeira nas 19 serrarias visitadas. 
Avaliou-se também a idade média do maquinário, a qual é uma variável importante para o setor de base florestal, pois maquinários obsoletos podem diminuir consideravelmente a eficiência do setor (BATISTA et al., 2015). Dessa forma, os resultados apontaram que 18 serrarias têm maquinário com a idade média de 11 a 20 anos e apenas uma apresentou maquinário com idade na faixa de 21 a 30 anos. Para LATORRACA (2004), serrarias de pequeno e médio porte apresentam o grau de automação baixo, podendo gerar grande desperdício de matéria-prima, o que foi verificado no presente estudo.

Além disso, todas as serrarias apresentaram infraestrutura básica composta por galpão de máquinas, pátio sem cobertura e piso cimentado para o armazenamento das toras e apenas 11 empresas apresentaram estocagem considerada correta da madeira serrada, a qual deve ser estocada em local coberto, com piso de cimento e arejado, visando acelerar a secagem da madeira. Ademais, quatro apresentaram estufas e caldeiras para a secagem artificial da madeira.

O consumo de madeira anual nas 19 serrarias foi em média de $12 \mathrm{mil} \mathrm{m}^{3}$ de madeira em tora por ano, perfazendo um montante de 230,1 mil $\mathrm{m}^{3}$ nas 19 empresas, valor menor do que foi encontrado por SFB \& IMAZON (2010), os quais levantaram em 2009 o consumo de 670 mil m$^{3}$ de madeira em tora em 35 empresas da mesma região. Verificou-se certa discrepância entre o consumo anual das 19

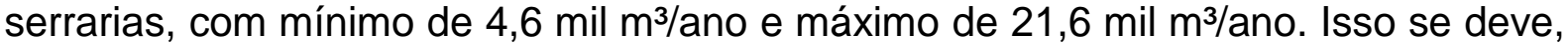
principalmente, ao porte dos empreendimentos.

No que diz respeito à produção de madeira serrada, as 19 empresas da $\mathrm{RMB}$ apresentaram média de $6,4 \mathrm{mil}^{3}$ por ano de madeira processada, com um montante de $122 \mathrm{mil} \mathrm{m}^{3}$ de madeira serrada anualmente. Esses valores foram inferiores aos encontrados pelo SFB \& IMAZON (2010), que, em 2009, quantificaram a produção de madeira no Município de Belém foi de 279 mil em 2009. Essa diferença é devido ao maior número de empresas (35) visitadas pelo referido instituto.

Nesta perspectiva, a madeira serrada é o principal produto obtido na forma de ripas, caibros, tábuas, pranchas e similares. Corroborando com isso, o SFB \& IMAZON (2010), levantaram que $72 \%$ das empresas do setor de base florestal produzem madeira serrada com baixo valor agregado (ripas, caibros, tábuas e similares); $15 \%$ transformam em madeira beneficiada (pisos, esquadrias, madeira aparelhada etc.); e o restante (13\%), em madeira laminada e compensada.

Para esse estudo, foram determinados uma média de rendimento operacional de $52 \%$ entre as 19 empresas, tendo como valor mínimo $37 \%$ e valor máximo de $65 \%$. FINOTTI et al. (2006), estudando o rendimento médio de serrarias do Brasil, encontraram rendimento na faixa de $60 \%$ a $80 \%$ em serrarias do Brasil, maior que a média encontrada nesta pesquisa. Essa diferença é devido ao maior aproveitamento das toras na região Sul e Sudeste. Dessa maneira, segundo ROCHA (2007), o rendimento operacional é a principal variável para analisar o sucesso do empreendimento.

A principal problemática envolvendo o rendimento operacional encontrado é o baixo aproveitamento da materia-prima. Com isso, diminuem-se os lucros, há uma grande geração de resíduos madeireiros e, por conseguinte, uma dificuldade na sua destinação, podendo, com isso, causar problemas socioambientais, caso não haja um plano de gerenciamento correto desse resíduos (HASAN et al., 2011; FIGUEREDO et al., 2013). 
Assim, a abundância de matéria-prima em determinadas regiões é um fator que pode contribuir para a grande geração de resíduos. Nesse sentido, DEMIRBAS (2011) explana que a quantidade de resíduos tem aumentado devido ao aumento da população humana. Por essas razões, os rendimentos obtidos por serrarias no desdobro da madeira variam de uma indústria para outra, sendo o diagnóstico fundamental para estabelecer as possibilidades de aproveitamento (CERQUEIRA, 2012; RIUL \& RIBEIRO, 2012; DELMIRO et al., 2015). Assim, a Figura 4 mostra o rendimento médio e a porcentagem do número de empresas pertencentes a cada classe.

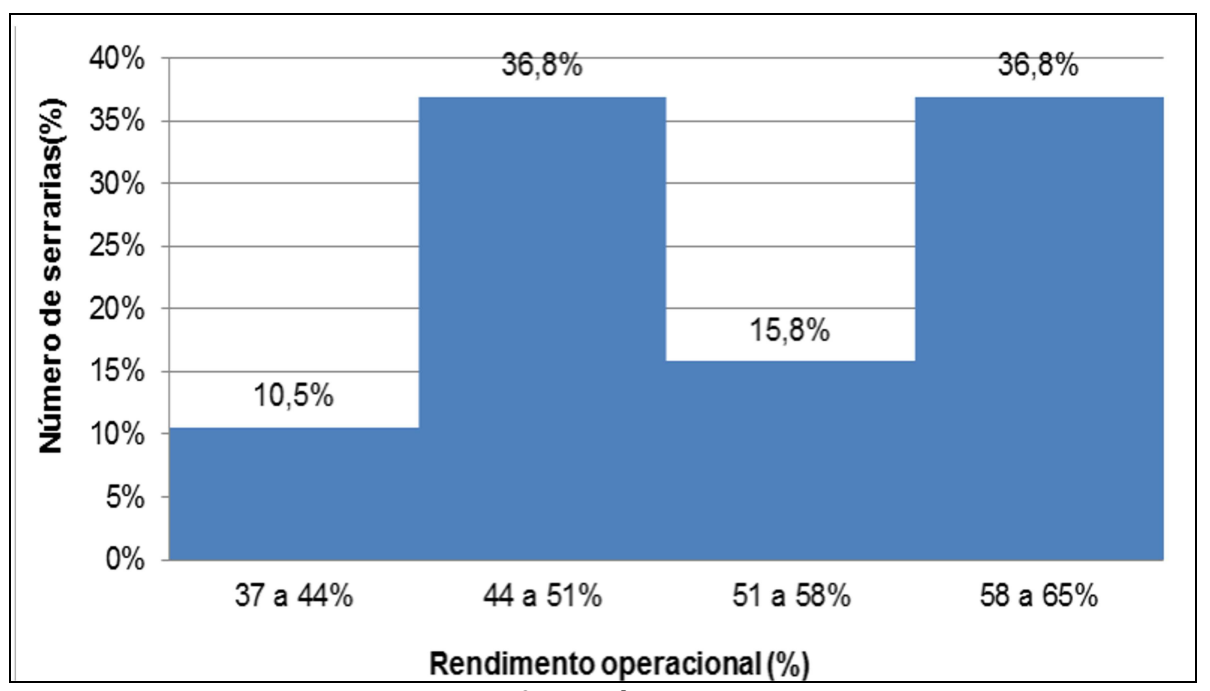

FIGURA 4 - Histograma de frequência do rendimento operacional das 19 serrarias visitadas.

Verificou-se que duas empresas (10,5\%) estiveram na faixa de $37 \%$ a $44 \%$ de rendimento operacional na Amazônia legal (SFB \& IMAZON, 2010); já sete empresas (36,8\%) estiveram na faixa de rendimento operacional de $44 \%$ a $51 \%$; três serrarias (15,8\%) rendimento de 51 a $58 \%$; e sete serrarias $(36,8 \%)$ estão dentro da faixa de 58 a $65 \%$, sendo considerado um rendimento operacional alto.

Neste sentido, BATISTA et al. (2013) encontraram rendimento operacional médio das serrarias brasileiras de $60 \%$ a $80 \%$, utilizando metodologia similar, através de entrevistas semi-estruturadas e estimativas feitas pelo balanço de materiais. Ademais, para FINOTTI et al. (2006), os menores rendimentos são vistos nas indústrias madeireiras que realizam o processamento primário, como as serrarias.

Realizando o Teste $t$ de Student (resumo amostral) para comparar o rendimento operacional encontrado $52,47 \%$ com o levantado pelo SFB \& IMAZON (2009) para o estado do Pará $(38,2 \%)$, verificou-se diferença estatisticamente significativa $(p<0,05)$. Assim, o rendimento operacional médio das serrarias do estado do Pará foi inferior ao observado nas serrarias da região metropolitana de Belém.

Diante do exposto, o rendimento operacional pode ser afetado por vários fatores, como layout da indústria madeireira, características e condições operacionais do maquinário, disponibilidade de energia, grau de mecanização e automação da serraria (VITAL, 2008). Para ROCHA (2007), o rendimento operacional também é influenciado por fatores, como produtos finais, características da espécie, mão de obra e, principalmente, diâmetro das toras. Considerando o contexto em que se encontra o setor madeireiro na região, investimentos em ENCICLOPÉDIA BIOSFERA, Centro Científico Conhecer - Goiânia, v.13 n.24; p.47 2016 
tecnologia, mão-de-obra qualificada e incentivos por parte do governo são fundamentais para o aumento do rendimento operacional, propocionando, com isso, elevação dos lucros das empresas e geração de emprego e renda.

\section{CONCLUSÃO}

A maior parte das serrarias apresenta porte pequeno idade média a alta, processando um elevado número de espécies florestais diferentes e utilizando, para esse processamento, maquinários básicos, como serra fita, serra circular e destopadeiras.

O consumo médio nas serrarias pesquisadas é de $12 \mathrm{mil} \mathrm{m} 3 / \mathrm{ano}$ de madeira em tora, com produção de 6,4 mil m³/ano de madeira processada. Os principais produtos obtidos são a madeira serrada, como ripas, caibros, tábuas, pranchas e similares, ao passo que o Rendimento operacional é inferior a média brasileira, porém maior que a média do estado do Pará a da Região Amazônica.

\section{REFERÊNCIAS}

BARBOSA, A. P.; VIANEZ, B. F.; VAREJÃO, M. D. J.; ABREU, R. L. S. D. Considerações sobre o perfil tecnológico do setor madeireiro na Amazônia Central. Parcerias Estratégicas, n 12, p. 43, set. 2001.

BATISTA, D. C.; DA SILVA, J. G. M.; CORTELETTI, R. B. Desempenho de uma serraria com base na eficiência e na amostragem do trabalho. Floresta Ambiente, v. 20, n. 2, jun. 2013. Disponível em < http://dx.doi.org/10.4322/floram.2013.005 >. Acesso em ago de 2015.

BATISTA, D. C., da SILVA, J. G. M.; de PAULA ANDRADE, W. S.; VIDAURRE, G. B. Desempenho operacional de uma serraria de pequeno porte do Município de alegre, Espírito Santo, Brasil. Floresta, Curitiba, PR, v. 45, n. 3, p. 487 - 496, jul. / set. 2015.

BECKER, B. K. Recuperação de áreas desflorestadas na Amazônia: será pertinente o cultivo da palma de óleo (dendê)? França: Confins. 2010. Disponível em <http://confins.revues.org/6609>. Acesso em jul de 2014.

BLAIR, R.C.; TAYLOR, R.A. Bioestatística para Ciências da Saúde. São Paulo: Pearson Education do Brasil, 2013.

CERqueiRA, P. H. A. D.; VIEIRA, G. C.; BARBeRENA, I. M., MELO, L. C.; FREITAS, L. C. D. Análise dos resíduos madeireiros gerados pelas serrarias do município de Eunápolis-BA. Floresta Ambiente, Seropédica , v. 19, n. 4, p. 506510, Dec. 2012. Disponível em <http://dx.doi.org/10.4322/floram.2012.051. Acesso em jul. de 2015.

DELMIRO, L. B; PEREIRA, K; PINTO, C. V. Diagnóstico das serrarias no Município de Alta Floresta-MT. Nativa-Revista de Ciências Sociais do Norte de Mato Grosso, v. 4, n. 2, 2015.

DEMIRBAS, A. Waste management, waste resource facilities and waste conversion processes. Elsevier / Energy Conversion and Management, 2011. p.1280-1287.

FIGUEREDO, D. C. V. de; SCHMIDT, R. C.; MIREK, Z. M.; RODRIGUES, L. A. Aspectos e impactos ambientais - uma visão da ENCICLOPÉDIA BIOSFERA, Centro Científico Conhecer - Goiânia, v.13 n.24; p.48 2016 
responsabilidade socioambiental de uma empresa de pequeno porte. Revista de Administração, FW, v. 11, n. 20, p. 134-149, Dez. 2013. Disponível em <http://revistas.fw.uri.br/index.php/revistadeadm/article/view/1077/1719. Acesso em jan. de 2016.

FINOTTI, A. R.; SCHNEIDER, V. E.; WANDER, P. R.; HILLIG, E.; SILVA, M. D. A. Uso energético de resíduos de madeira na cadeia produtiva de madeira/móveis e possibilidades de geração de créditos de carbono. In: Pólo Moveleiro da Serra Gaúcha. Sistemas de gerenciamento ambiental na indústria moveleira. Edusp; 2006.

GOMES, J.I.; SAMPAIO S.S. Aproveitamento de resíduos de madeira em três empresas madeireiras do Estado do Pará. Embrapa Amazônia Oriental, Comunicado Técnico 102, Belém, 2004.

HASAN, A. R.; GABRIELE, H. S.; TOWNSEND. Online sorting of recovered wood waste by automated XRF-technology: Part II. Sortingefficiencies. Elsevier / Waste Management, p. 695-704, 2011.

IBGE - INSTITUTO BRASILEIRO DE GEOGRAFIA E ESTATÍSTICA. Bases Cartográficas. Brasília,DF: Instituto Brasileiro de Geografia e Estatística, 2010.

IWAKIRI, S.; VIANEZ, B. F.; WEBER, C.; TRIANOSKI, R.; ALMEIDA, V. C. Avaliação das propriedades de painéis aglomerados produzidos com resíduos de serrarias de nove espécies de madeiras tropicais da Amazônia. Acta Amazonica, v. 42, n. 1, p. 59-64, 2012. Disponível em <http://dx.doi.org/10.1590/S0044-59672012000100007. Acesso em jan. de 2016.

LATORRACA, J. V. F. Processamento mecânico da madeira. Seropédica: Universidade Federal Rural do Rio de Janeiro, 2004. 116 p.

MELO, L. E. de L.; SILVA, C. de J.; LOPES, K. V.; DE BRITO, P. G. M.; SANTOS, I. S. Resíduos de serraria no estado do Pará: caracterização, quantificação e utilização adequada. Floresta e Ambiente, v. 19, n. 1, p.113-116, 2012. Disponível em http://dx.doi.org/10.4322/floram.2012.012. Acesso em set. de 2015.

NUNES, P. A.; DE MELO, C. O.; TEIXEIRA, D. A participação do setor madeireiro na economia das microrregiões geográficas do Paraná - 2009. Revista Brasileira de Agropecuária Sustentável, RBAS, v.2, n.1, p.8-20, Jul. 2012. Disponível em <http://dx.doi.org/10.21206/rbas.v2i1.53. Acesso em out. de 2015.

PAIXÃO, C. P. S.; FERREIRA, E.; STACHIW, R. Produção e destinação dos resíduos gerados em serrarias no município de Rolim de Moura - RO. Revista Brasileira de Ciências da Amazônia, v. 3, n. 1, p. 47-56, 2014.

PARÁ. Secretaria de Estado de Planejamento, Orçamento e Finanças. Instituto de Desenvolvimento Econômico, Social e Ambiental do Pará. Estatística municipal de Belém. Belém, PA, 2014.

PRODANOV, C. C.; FREITAS, E. C. Metodologia do trabalho científico: métodos e técnicas da pesquisa e do trabalho acadêmico. 2. ed. Novo Hamburgo/RS: Universidade FEEVALE, 2013. 
REZENDE, A. M.; SILVA, M. L. da; SOARES, N. S.; DE MOURA, A. D.; MENDES, T. F.; COSTA, C. B. Perspectivas econômicas atuais exigem mudanças para melhorar desempenho do setor florestal em 2014. Ciflorestas, 2014.Disponível em:www.ciflorestas.com.br/download.php?tabela=analises\&id=62\&leitura $=s$. Acesso em 17 de out. 2014.

RIUL, M.; RIBEIRO E. L. Diagnóstico e Diretrizes para a Gestão de Resíduos no APL de Móveis de João Pessoa-PB. UNOPAR Científica Ciências Exatas e Tecnológicas. Londrina, v. 11, n. 1, p. 15-24, Nov. 2012.

RIVERO, S.; ALMEIDA, O.; DO ROSÁRIO, L. F.; RODRIGUES, L. F.; AROUCK, J. H. S.; FERNANDEZ, R. D. Instituições, gestão dos recursos naturais e o setor madeireiro no Estado do Pará. Amazônia: Ciência \& Desenvolvimento., Belém, v. 7, n. 13, jul./dez. 2011.

ROCHA, M. P. Técnicas de serrarias. In: OLIVEIRA, J. T. S.; FIEDLER, N. C.; NOGUEIRA, M. (Org.). Tecnologias aplicadas ao setor madeireiro. Jerônimo Monteiro: Suprema, 2007.

ROCHA, M. P. Técnicas e planejamento em serrarias. Curitiba: FUPEF, 2002. 121 p.

SCARIOT, Nádia. A Evolução do Estado na Perspectiva da Questão Ambiental. Editora: UPF. Passo Fundo- RS. 2011.p. 232.

SFB - SERVIÇO FLORESTAL BRASILEIRO e IMAZON - INSTITUTO DO HOMEM E MEIO AMBIENTE DA AMAZÔNIA. A atividade madeireira na Amazônia brasileira: produção, receita e mercados. Belém, PA: Serviço Florestal Brasileiro (SFB); Instituto do Homem e Meio Ambiente da Amazônia (IMAZON), 2010. 31p.

SFB - SERVIÇO FLORESTAL BRASILEIRO. Florestas do Brasil em resumo 2013: dados de 2007-2012. / Serviço Florestal Brasileiro. - Brasília, DF: SFB, 2013.

SILVA, L. C. R. da; MARQUES, G. de S. Análise do setor madeireiro paraense: crises e perspectivas. Amazônia: Ciência \& Desenvolvimento. Belém, v. 8, n. 15, jul./dez. 2012.

VALVERDE, A.; REZENDE, A. M.; SILVA, M. L. D.; MOURA, A. D. D.; SOARES, N. S.; MENDES, T. F.; RÊGO, L. J. S. Mercado externo de produtos florestais se apresenta como uma opção à economia interna desaquecida. Ciflorestas, 2014. Disponível em: <http://www.ciflorestas.com.br/arquivos/a_n_desaquecida_19 223.pdf>. Acesso em 07 de out. 2014.

VERÍSsIMO, A.; SOUZA JR, C.; CELENTANO, D.; SALOMÃO, R.; PEREIRA, D.; BALIEIRO, C. Áreas para produção florestal manejada: Detalhamento do Macrozoneamento Ecológico Econômico do Estado do Pará. Relatório para o Governo do Estado do Pará, 2006.

VITAL B. R. Planejamento e operações de serrarias. Viçosa: UFV; 2008. 